Protestantismo em Revista é licenciada sob uma Licença Creative Commons.

http://dx.doi.org/10.22351/nepp.v45i1.3041

\title{
A PALAVRA QUE RETUMBA DESCENDO DO ALTO: A EXPERIÊNCIA NUMINOSA DE LUTERO E A HIEROFANIA NO TEXTO SAGRADO
}

\author{
The Word that echoes high down: \\ the Luther's numinous experience and hierophany in the sacred text
}

Elvio Nei Figur *

\begin{abstract}
Resumo
Martinho Lutero, em seus escritos teológicos, faz transparecer em diversos momentos aquele que é considerado o ponto de partida e centro de sua teologia - a justificação do pecador por graça e fé. Em alguns relatos ele o descreve como originário de uma experiência mistico existencial, e em outros, mais como de uma descoberta intelectual. $\mathrm{O}$ artigo busca refletir aspectos do tema a partir dos relatos míticos repetidos no luteranismo posterior e de escritos do próprio reformador buscando identificar a presença de uma experiência numinosa e de uma hierofania na leitura que Lutero faz do texto sagrado.

Palavras-chave

Cristianismo. Luteranismo. Numinoso. Hierofania.
\end{abstract}

\begin{abstract}
Martin Luther, in his theological writings, does transpire at various times what is considered the starting point and center of his theology - the justification of sinner by grace and faith. In some reports he describes as originating in an existential mystical experience, and other, more like an intellectual discovery. The article seeks to reflect aspects of the topic from repeated mythical stories in later Lutheranism and writings of the reformer seeking identify the presence of a numinous experience and a hierophany reading that Luther is the sacred text.

Keywords

Cristianity. Lutheranism. Numinous. Hierophany.
\end{abstract}

[Texto recebido em junho de 2017 e aceito em julho de 2018, com base na avaliação cega por pares realizada por pareceristas ad hoc]

* Elvio Nei Figur. Mestre em Ciência da Religião pela Universidade Federal de Juiz de Fora, MG (UFJF). Email: elviofigur@gmail.com 
A Palavra que nos é falada na Escritura, no sermão e no sacramento [...] É uma palavra que 'retumba descendo do alto'

(Philip S. Watson)

\title{
Introdução
}

\begin{abstract}
Castelo forte é nosso Deus, defesa e boa espada; Da angústia livra desde os céus nossa alma atribulada. Investe Satã com hábil afã. E sabe lutar com força e ardil sem par; Igual não há na terra.

Sem força para combater, teríamos perdido. Por nós batalha e irá vencer quem Deus tem escolhido. Quem é vencedor? Jesus Redentor, o próprio Jeová, pois outro Deus não há; Triunfará na luta.

O mundo venham assaltar demônio mil, furiosos. Jamais nos podem assombrar, seremos vitoriosos. Do mundo o opressor, com todo rigor julgado ele está; Vencido cairá/por uma só palavra.

O Verbo eterno ficará, sabemos com certeza. E nada nos perturbará com Cristo por defesa. Se vierem roubar os bens, vida e o lar - Que tudo se vá! Proveito não lhes dá. O céu é nossa herança. ${ }^{1}$
\end{abstract}

Foi dessa forma que Martinho Lutero, por volta de e 1528, inspirado no salmo 46 esboçou em versos aquilo que sentia em seu íntimo e que o havia motivado, alguns anos antes, a publicar as 95 teses que desencadeariam o movimento conhecido como Reforma Protestante. Para Martinho Lutero, a música é uma das mais belas dádivas divinas, pois ela, associada à mensagem cristã, teria a capacidade de transformar os homens como ele afirma: “Não pode haver má intenção onde houver companheiros cantando bem [...] Para a palavra e verdade divina ela silencia e prepara o coração" ${ }^{2}$. Assim, para o reformador, a canção musicada tem a capacidade de despertar o espírito para o numinoso.

Rudolf Otto (2007) em O Sagrado define por Hinos Numinosos aqueles que transmitem tal sentimento. Ein Feste Burg de Lutero é um desses hinos pois nele o autor descreve sua experiência místico existencial como um tempo de luta contra o hábil afã de Satã, o inimigo a quem o homem, por si só, não poderia vencer, mas que seria vencido pelo próprio Jeová. Por outro lado, no mesmo hino, Lutero também expressa seu encontro com as escrituras sagradas do cristianismo que lhe teriam mostrado que no Verbo Eterno ele, pessoalmente, encontraria defesa, abrigo e a herança eterna. Nas palavras de Otto, esses são "aspectos obscuros muito originais e ao mesmo tempo muito pessoais, secretos, quase que inquietantemente misteriosos" de Lutero. Trata-se, continua, "de uma consciência em primeira mão do sentimento numinoso"3.

O presente artigo, partindo dos relatos míticos do luteranismo posterior e de textos do próprio reformador, aborda a 'gênese' daquilo que é tido como ponto de partida e centro da teologia de Lutero - a justificação do pecador por graça e fé - com o propósito de delinear

Ein Feste Burg - letra e melodia de Martinho Lutero, 1528. Trad. Rodolfo Hasse, Hinário Luterano, p. 165.

LUTERO, Martinho. Martinho Lutero: Obras Selecionadas. Vol. 07 Porto Alegre: Concórdia; São Leopoldo: Sinodal, 2000. p. 483.

3 OTTO, Rudolf. O Sagrado. São Leopoldo: Sinodal; Petrópolis: Vozes, 2007. p. 135. 
alguns aspectos centrais presentes tanto na experiência numinosa como na descoberta intelectual do reformador como uma hierofania.

\section{Lutero: Contexto e Biografia}

Martin Luder nasceu em 10 de novembro de 1483 em Eisleben. Batizado no dia seguinte, recebeu o nome do santo do dia. Seu sobrenome só seria alterado para Luther quando da sua segunda experiência religiosa mais marcante. Seu pai Hans era filho de agricultores e natural de Mohra, na Turingia e a mãe, Margaretha, nascida em Ziegler, provinha de círculos burgueses ${ }^{4}$.

Lutero foi um monge agostiniano e professor de Bíblia na Universidade de Wittemberg na Alemanha. É considerado como a figura mais central da Reforma Protestante, pois é ele quem, com maior êxito, se levanta contra diversos dogmas do catolicismo romano de sua época, contestando, primordialmente, a doutrina de que o perdão dos pecados poderia ser obtido por meio dos breves de indulgência comercializados pela Igreja daquela época. Essa sua discordância o levaria a publicar, em 31 de outubro de 1517, as chamadas 95 teses em aberta discordância especialmente com o vendedor de indulgências João Tetzel. Ao ser chamado a retratar suas teses e seus escritos posteriores diante da dieta de Worms, ocorrida entre 28 de janeiro e 25 de maio de 1521, sua prévia experiência pessoal e sua descoberta intelectual/teológica da justificação pela fé, o levariam a proclamar, diante do Imperador Carlos $\mathrm{V}$ e de todas as lideranças políticas e religiosas ali reunidas, o seguinte:

\footnotetext{
A menos que seja vencido e convencido com testemunhos das Sagradas Escrituras, ou com razões e princípios claros e irrefutáveis e estando eu convencido pelos versículos que citei e tendo minha consciência presa na Palavra de Deus, não posso e não quero retratar-me, pois não é bom e aconselhável que se faça qualquer coisa contra a consciência. Aqui estou; não posso de outra forma! Que Deus me ajude! 5
}

Ante sua recusa em retratar-se Lutero é expulso da Igreja Romana e, consequentemente, passa a ser condenado como um fora da lei pelo Sacro império RomanoGermânico. No entanto, ele recebeu proteção do príncipe-eleitor da Saxônia, Frederico, o sábio, que o manteve em secreto no castelo de Wartburgo onde continuou com suas publicações e traduções da Bíblia para a língua alemã.

Desencadeava-se assim o movimento conhecido como a Reforma Protestante que, no entanto, foi muito além de um movimento religioso: Os camponeses viram aí a justificativa para os seus anseios; os humanistas, teólogos e monges que objetavam contra a Roma 'pagã e mercantil', e que ansiavam por algum tipo de reforma, perceberam em Lutero esta possibilidade 6 . Cada grupo, a seu modo e de acordo com os seus interesses, apropriou-se e

\footnotetext{
DREHER, Martin N. História do povo de Jesus. São Leopoldo: Sinodal, 3013. p. 230.

JUST, Gustav. Deus despertou Lutero. Porto Alegre: Concórdia, 2003. p. 78-79.

6 FEBVRE, Lucien. Martinho Lutero, um destino. São Paulo: Três Estrelas, 2012.
} 
divulgou as ideias de Lutero, seja por razões políticas, pessoais, econômicas, sociais ou religiosas. As motivações de Lutero, no entanto, nasceram muito mais de uma preocupação íntima e pessoal. Elas foram, antes de tudo, inquietações pela salvação de sua alma e de busca por paz para sua vida pessoal que encontrariam ressonância em textos sagrados do cristianismo.

Nos relatos que descrevem o que seria a 'gênese' daquilo que é considerado como ponto de partida e centro da teologia de Lutero evidencia-se dois aspectos fundamentais. $\mathrm{O}$ primeiro deles é a presença de uma experiência numinosa em que se evidencia a experiência mistico existencial, e o segundo, a descoberta intelectual que funciona como uma hierofania. Nela o Deus se revela, ou se manifesta, no e através do texto sagrado. Os dois aspectos estão imbricados no caso de Lutero de forma que experiência existencial subjetiva e racionalidade chegam, de alguma forma, a se 'confundir'.

\section{As experiências místico existenciais de Lutero}

A experiência religiosa, é uma referência fundamental na compreensão e na própria manutenção das diferentes religiões. Para R. Otto (2007), as religiões surgem de um sentimento que é anterior à racionalização por meio de doutrinas e dogmas. Esse 'momento' ele chama de numinoso. Trata-se de um termo, por ele cunhado, a fim de designar "o sagrado descontado do seu aspecto moral e [...] descontado, sobretudo, do seu aspecto racional" (p. 38). O numinoso é, portanto, o elemento irracional, o 'objeto vivo' na experiência religiosa, o 'estado psíquico' que somente pode ser comunicado ao se conduzir o ouvinte "mediante exposição àquele ponto da sua própria psiquê" ${ }^{\prime \prime}$. Chamaremos aqui esse sentimento de experiência do numinoso. Por outro lado, M. Eliade (1992), ao falar da Hierofania a descreve como "a manifestação de algo 'de ordem diferente' - de uma realidade que não pertence ao nosso mundo - em objetos que fazem parte integrante do nosso mundo 'natural', 'profano'"8. Tal manifestação do sagrado no 'profano' constitui-se de uma experiência criadora de uma 'nova realidade' pois ela instala uma 'nova ordem' na mente de quem crê e este, a partir da manifestação, reinterpreta o mundo a sua volta com base nessa experiência. Observa-se assim que, tanto Otto, quanto Eliade consideram que algum tipo de experiência, seja qual tipo for, acontece com todo fiel, em maior ou menor intensidade, e é dessas experiências que se desenvolvem as religiões.

Gustav Just, no livro Deus despertou Lutero, traz uma descrição dos relatos míticos ou experiências de Martinho Lutero e que são repetidos nos discursos internos ao luteranismo e podem ser classificados como experiências místico-existenciais e/ou eventos hirofânicos. O autor começa descrevendo a relação de Martinho com a rígida disciplina paterna e a educação no temor de Deus. Segundo Just, " assim como no lar, também na escola a disciplina era muito rígida. Ali havia um desses professores que tratavam seus alunos

\footnotetext{
OTTO, 2007, p. 39.

8 ELIADE, Mircea. O sagrado e o profano. Trad. Rogério Fernandes. São Paulo: Martins Fontes, 1992. p. 16.
} 
como carcereiros e carrascos tratam os ladrões. Certa vez, Lutero foi castigado quinze vezes com vara durante uma manhã"9. O ensino religioso que recebia na escola e na Igreja, segundo o autor, contribuía mais para intimidar do que para educar:

É bem verdade que, na noite de Natal, se cantava nas igrejas: “Jesus menino hoje nasceu". Mas em vez da grande mensagem de alegria: "Hoje vos nasceu o salvador", pregava-se na escola o fogo e os tormentos do inferno. Lutero assim se expressa: "Desde criança, me acostumaram a sentir-me assustado apenas ouvindo pronunciar o nome de Cristo, pois não me ensinaram outra coisa senão que ele era um juiz severo e cheio de ira. Todos éramos orientados no sentido de que nós mesmos deveríamos expiar nossos pecados, mas, sendo-nos impossível fazer tanta penitência e praticar tantas boas obras como era necessário, eles nos encaminhavam aos santos no céu, nos ensinavam a invocar o nome da virgem Maria, para que ela, intercedendo por nós, desviasse de nós a ira de Cristo e alcançasse para nós a sua graça." 10

Em 1498, Lutero foi estudar em Eisenach. Lá, para se sustentar, ele cantava em frente às casas de pessoas ricas em troca de moedas. Lutero se destacava entre seus colegas, especialmente ao discursar, tanto que foi convidado pelo próprio reitor da Universidade de Erfut para estudar ali. Foi em Erfurt que ele recebeu o título de bacharel em artes da Faculdade de Filosofia em 1502, e em 1505, de mestre em Artes. Em seguida ingressaria no curso de Direito atendendo, assim, ao desejo de seu pai.

Os relatos da vida de Lutero dão conta de que, por mais de uma vez, ele teria pensado na morte e julgado estar perto dela. Certa vez teria se ferido na coxa com um espadim que costumava carregar na cintura. Só com muito custo teria conseguido estancar o sangue enquanto um amigo corria em busca de ajuda médica. Nesse dia Lutero teria sentido a angustia da morte se aproximando e teria implorado ajuda à Virgem Maria. Pouco tempo depois desse incidente, Lutero teria perdido um amigo muito próximo de forma repentina. "Esse fato", segundo Just (2003),

[...] o deixou profundamente confuso e, em tal estado de ânimo, ele exclamou muitas vezes: "Oh! Quando serás uma pessoa piedosa e arrependida a fim de conseguires para ti um Deus gracioso?". Então uma voz interior lhe dizia mais forte do que nunca: "Lá adiante estão os muros deteriorados do convento dos monges agostinianos; eles acenam para ti e te convidam: Aqui entre nós, longe dos rumores do mundo, a tua alma aflita encontrará paz e descanso."11

Sobre suas infindáveis angustias, anos depois, Lutero teria dito:

Terrível. Implacável. Assim eu via o Senhor. Ele nos punia em vida e nos enviava ao purgatório após a morte ou nos enviava para as chamas do inferno antes do descanso eterno. Mas estava errado. Quem vê um Deus enfurecido [...] não o vê com clareza [...] mas o vê através de um véu [...] como se uma tempestade escura escondesse a sua face. Se realmente acreditarmos que Cristo é o nosso salvador,

\footnotetext{
JUST, 2003, p. 41-42.

10 JUST, 2003, p. 42.

11 JUST, 2003, p. 48.
} 
então temos um Deus de amor. E se tivermos fé em Deus significa olhar para Seu coração generoso. Então se o demônio jogar seus pecados em seu rosto. E disser que merecem a morte e o inferno, respondam; Eu admito que mereço a morte e o inferno, e daí? Pois sei de Alguém que sofreu e morreu na cruz para me redimir. Seu nome é Jesus Cristo, o filho de Deus! E onde Ele estiver, eu também estarei.12

A fim de recobrar a saúde, Lutero voltara à casa dos pais em Mansfeld. Na volta a Erfurt, em 2 de julho de 1505, quando ainda estava em Stotterheim, seis quilômetros ao norte de Erfurt, desencadeou-se, de repente, uma tremenda tempestade. Um raio teria caído ao seu lado seguindo-se um estrondoso trovão ${ }^{13}$. Caído ao chão, pensou que morreria naquele dia, por isso fez uma promessa para Santa Ana de que, se saísse com vida daquela tempestade, ingressaria no convento dos monges agostinianos na cidade de Erfurt, pois só assim, achava ele, de fato poderia reconciliar-se com Deus e encontrar a tão desejada paz espiritual. É provável que Martinho tenha visto no acontecimento uma espécie de revelação vinda de Deus ${ }^{14}$ pois, em 17 de julho de 1505, mesmo sem o conhecimento dos pais, ele entraria no mosteiro dos agostinianos eremitas observantes em Erfurt na condição de noviço.

Segundo Just (2003), o mosteiro era um dos mais rigorosos e a tão esperada paz para a alma não seria encontrada tão cedo. Ali Lutero se afligia e atormentava com jejuns, orações e vigílias, mas sem sucesso. Mais tarde ele teria escrito; "se alguma vez um monge ganhou o céu através da vida monástica, então eu também entraria nele"15.

Lutero fez seus votos solenes em setembro de 1506 e em 3 de abril de 1507 foi ordenado sacerdote. Em 2 de maio de 1507 celebrou sua primeira missa, oportunidade em que quase teria fugido do altar por julgar-se indigno de realizar o sacrifício da missa diante da majestade divina. Nessa ocasião teria ocorrido ainda um confronto com seu pai que lhe teria apontado o quarto mandamento e se negado a ver no acontecimento de Stotternheim algum tipo de 'chamado divino'. Para o pai, a ordem do mandamento era mais clara do que a experiência ${ }^{16}$.

Nota-se, em primeiro lugar, nesses relatos e experiências numinosas de Lutero aquilo que Otto (2007) chama de sentimento de criatura. Esse sentimento é aquele que 'anula' o ser "perante o que está acima"17. Trata-se, em Lutero, daquele sentimento de impotência e indignidade diante da majestade divina; um sentimento confesso de dependência. Ligado ao sentimento de criatura está também o aspecto que Otto chama de mysterium tremendum entendido como temor. É aquele 'algo' arrepiante e temível mas que é, ao mesmo tempo, misterioso e abscondido. É a 'divina majestade' e a 'onipotência de Deus' em contraste com sua 'graça'; o Deus 'terrível e implacável' em contraste ao 'Deus de amor'. Ao ser

12 Se desconhece a fonte dessa citação que replicada no luteranismo e atribuída ao Reformador.

13 O filme Luther dirigido por Eric Till mostra muito bem a angustia e o que teria sido a experiência religiosa determinante na mudança de rumo e percepção da vida por parte de Martinho Lutero.

14 DREHER, 2013.

15 JUST, 2003, p. 51.

16 Segundo Dreher (2013), possivelmente em vista desse confronto é que Lutero teria optado pela vida acadêmica ao invés do sacerdócio.

17 OTTO, 2007, p. 41. 
confrontado com o Deus justo e irado, o inaproximável torna-se aproximável. O sagrado distante torna-se próximo e paradoxalmente profano. O majestático torna-se algo familiar mostrando a face amorosa de Deus. No Catecismo Menor isso fica expresso no início de cada explicação que Lutero dá aos Mandamentos do decálogo; “Devemos Temer e Amar a Deus [...]"18. "Essa harmonia de contrastes é o âmago da religião de Lutero"19. Aí está outro aspecto da experiência numinosa chamado por Otto de Fascinante; "o que o demoníaco-divino tem de assombroso e terrível para a psique, ele tem de sedutor e encantador" 20 .

O Augustum é o aspecto do numinoso que se refere à desvalorização da própria pessoa e de toda a existência frente ao numinoso. Trata-se, para Otto, de um sentimento de absoluta profanidade. Diante do numinoso a pessoa sente a necessidade de respeito absoluto, elevado, sem que isso, necessariamente, seja logo tomado por exigências morais. É uma obrigação íntima não pela simples coerção pelo avassalador ou assombroso, mas pelo curvar-se em reconhecimento diante do mais sagrado valor. Nesse aspecto entra a questão da remissão, cobertura ou expiação. Enquanto profano não se tem a dignidade de proximidade com o Augusto. Para Otto, é no cristianismo que esse mistério da necessidade de expiação exprime da forma mais profunda. Lutero tem justamente essa questão como central. Sua preocupação maior era justamente a questão da salvação pessoal já que ele se via indigno diante de Deus. Esse Deus, para Lutero, inicialmente era visto como personificação da Justiça que, por sua vez, era compreendida no âmbito semântico político. Sua experiência numinosa seria o que teria lhe indicado uma 'nova' forma de compreender essa Justiça Divina. Lutero passa a compreendê-la num sentido teológico diferente, ou seja, que Deus justifica através da fé no Cristo. A expiação, redenção, cobertura passa a ser compreendida como algo dado, um feito gracioso de Deus que dá o céu como herança gratuita Conforme ele se expressa no hino citado acima. Para Lutero, é a divindade que religa, aproxima o profano do sagrado através do Cristo encarnado. Em Cristo, por graça mediante fé, segundo a teologia luterana, o ser humano se torna digno da proximidade com o augusto, apesar de permanecer um pecador indigno por sua natureza.

\section{A hierofania no texto sagrado}

Dissemos acima que, para M. Eliade (1992), a Hierofania é uma manifestação de algo 'de ordem diferente' em objetos que integram nosso mundo 'profano' e que tal manifestação constitui-se, por conseguinte, de uma experiência criadora de uma 'nova ordem', ou de uma nova visão da realidade. Lutero não apenas interpreta a experiência do raio e do forte estrondo como uma espécie de 'chamado' ou 'revelação' divina que lhe indicaria onde ele poderia encontrar a almejada paz interior, mas ele compreende o acontecimento como uma manifestação hierofânica do Deus no qual ele crê. A partir daí toma a decisão de entrar no mosteiro, mesmo contra a vontade dos pais. Nota-se a força da hierofania que instaura no

18 LUTERO, 2000, p. 451-454.

19 OTTO, 2007, p. 138.

20 OTTO, 2007, p. 68. 
jovem Lutero a convicção de que fora, de fato, salvo pela divindade. Entretanto, a hierofania que de fato parece ser mais marcante na vida do reformador é aquela que acontece de forma mais racional do que normalmente se admite. Trata-se do 'encontro' ou da 'nova compreensão' do texto sagrado.

Como dissemos, Lutero buscava constantemente encontrar paz para sua alma; “De modo semelhante a Jacó [Gênesis 32.22-30] [...] lutou com Deus até compreendê-lo como o senhor soberano que tem amor profundo para com suas criaturas, mesmo caídas" 21. Mas não teria sido na vida nem na prática do monastério, e sim nas escrituras sagradas do cristianismo ele teria encontrado a almejada paz.

Teria sido na Biblioteca da universidade de Erfurt que Martinho Lutero viu-se, pela primeira vez, diante de um exemplar das escrituras. Naquela ocasião, segundo Just, ao examinar o Antigo Testamento, Lutero "deparou-se com a história de Samuel e sua mãe Ana, que ele leu com avidez e coração transbordante de alegria, desejando que Deus um dia, também lhe desse um desses livros de presente e fizesse dele um piedoso Samuel" 22 .

Mais tarde, entre novembro de 1510 e fevereiro de 1511, Lutero viajaria para Roma de onde retornaria decepcionado com a venda de indulgências e outras práticas presente na Igreja romana e que, no seu entendimento, não coadunavam com os ensinamentos bíblicos. Em 1512 Lutero receberia das mãos do Dr. Carlstadt o diploma de doutor em Teologia e assumiria a cadeira de lector in Bíblia no lugar de Staupitz na Faculdade de Teologia da Universidade de Wittemberg. $\mathrm{O}$ texto sagrado passou a fazer parte constante na vida de Lutero, de tal forma que quando, entre 1513 a 1519, ele lecionou sobre os Salmos, Romanos, Gálatas e Hebreus, teriam ocorrido dois fatos importantes: O primeiro é o episódio da divulgação das 95 teses $^{23}$, e o segundo, a (re)descoberta da justificação por graça e fé. $\mathrm{O}$ primeiro episódio é datado em 31 de outubro de 1517, e o segundo - que nos interessa de forma especial - não é possível datar.

Segundo alguns historiadores, um dos alunos de Lutero na Universidade de Wittenberg e que participava das conversas à mesa, teria divulgado que o momento da (re)descoberto a doutrina da justificação pela fé pelo reformador teria se dado in cloaca24. Esse aluno teria chegado a fantasiar dizendo que, enquanto o professor aliviava o ventre, aliviaria também a consciência do pavor do pecado. Outros, no entanto, afirmam que a experiência teria acontecido na torre do mosteiro agostiniano em Erfurt, daí o nome Experiência da Torre. O fato é que não é possível datar a experiência. Sabe-se apenas que deve ter ocorrido entre

21 FISCHER apud LUTERO, Martinho. Martinho Lutero: Obras Selecionadas. Vol. 01. Porto Alegre: Concórdia; São Leopoldo: Sinodal, 1992. p. 09.

22 JUST, 2003, p. 47.

23 Em 31 de outubro de 1517, Lutero teria pregado, nas portas da Catedral de Wittemberg, 95 teses propondo um debate sobre o valor das indulgências. $O$ propósito era provocar um debate acadêmico buscando a superação dessa prática considerada abusiva por Lutero. As críticas por ele tecidas nas 95 teses eram oriundas de sua preocupação como cura d'almas, já que assumira também a condição de pároco da igreja de Wittemberg.

24 In cloaca no sentido folclórico e no jargão dos monastérios quer dizer 'na pior'. 
1512 e 1518. Lutero fala de uma (re)descoberta que lhe proporcionara compreensão totalmente nova do evangelho e da justiça de Deus, apenas a partir de 1532. De qualquer forma, por volta de 1517 ele já tinha evoluído nos estudos das escrituras e de Santo Agostinho, para perceber que havia algo fundamentalmente errado, do ponto de vista da compreensão agostiniana, na forma como a Igreja Católica apregoava as indulgências.

No prefácio ao primeiro volume da edição completa dos escritos latinos, de 1545 sem mencionar datas, o reformador descreve o acontecimento. Ele lecionaria pela segunda vez sobre o livro dos Salmos sentindo-se melhor preparado após ter lecionado sobre as epístolas de Paulo aos Romanos, Gálatas e sobre a carta aos Hebreus. Ocorre que, enquanto lecionava, lhe perturbava uma passagem de Romanos; “A Justiça de Deus se revela no Evangelho, de fé em fé, como está escrito; O justo viverá por fé" ${ }^{25}$. De acordo com a teologia tradicional da época, de traços aristotélicos, a justiça revelada no evangelho consistiria nas exigências de Jesus como novo Moisés (foro político). Lutero então refletia; “Como se não bastasse que as leis do Antigo Testamento me exigem mais do que posso dar, vem ainda o evangelho acrescentar novas exigências"26. A epifania/luz que Lutero teve teria sido uma súbita compreensão da conexão entre as duas partes dessa passagem de Paulo. Foi como se "um raio de luz divina brilhasse em seu entenebrecido coração" 27, e ele teria passado a compreender que a expressão 'A Justiça de Deus revelada no Evangelho' deveria ser entendida em sentido passivo, ou seja, que Deus é o ator, ele é quem justifica por sua misericórdia (foro teológico).

Lutero explica sua experiência assim;

Eu odiava de Romanos 1.17 a expressão "Justiça de Deus", pois aprendi a entendêla filosoficamente como a justiça segundo a qual Deus é justo e castiga os pecadores injustos.

Eu não amava o Deus justo, que pune os pecadores; ao contrário, eu o odiava. Mesmo quando, como monge, eu vivia de forma irrepreensível, perante Deus eu me sentia pecador, a minha consciência me torturava muito. Eu andava furioso e de consciência confusa. Não obstante, teimava impertinentemente em bater à porta dessa passagem; desejava com ardor saber o que Paulo queria dizer com ela. Aí Deus teve pena de mim. Dia e noite eu andava meditativo, até que, por fim, observei a relação entre as palavras: "A Justiça de Deus é nele revelada como está escrito: o justo viverá por fé". Aí passei a compreender a justiça de Deus como sendo uma justiça pela qual o justo vive através da dádiva de Deus, ou seja, da fé. Comecei a entender que o sentido é o seguinte: Através do Evangelho é revelada a justiça de Deus, isto é, a justiça através da qual o Deus misericordioso nos justifica pela fé, como está escrito: "O justo vive por fé" 28 . Então me senti como renascido, e entrei

25 BÍBLIA, 2012, Romanos 1.17.

26 LUTERO, Martinho. Pelo Evangelho de Cristo: Obras Selecionadas de momentos decisivos da Reforma. Porto Alegre: Concórdia; São Leopoldo: Sinodal, 1984. p. 11.

27 LAWSON, Steven J. A Heroica Ousadia de Martinho Lutero. São José dos Campos: Fiel, 2013. p. 30.

28 Assim, na teologia posterior de Lutero, o termo justiça assume dois âmbitos semânticos, um propriamente teológico e o outro político. Isso, no entanto, não é novo, pois no mesmo prefácio às edições latinas de 1545 ele mesmo esclarece; "Mais tarde li o escrito de Santo Agostinho 'O Espírito e a Letra', onde, inesperadamente, constatei que também ele interpretava 'justiça de Deus' de forma semelhante: como uma justiça com a qual Deus nos veste ao nos justificar" (LUTERO, 1984, p. 31). 
pelos portões do próprio paraíso. Aí toda a Escritura me mostrou uma face completamente diferente. Fui passando em revista a Escritura na medida em que a conhecia de memória, e também em outras palavras encontrei as coisas de forma semelhante [...] Assim como antes eu havia odiado violentamente a frase "justiça de Deus", com igual intensidade de amor eu agora a estimava como a mais querida ${ }^{29}$.

Nesse relato o reformador descreve a hierofania que lhe instaura não apenas de uma nova compreensão do texto, mas uma nova realidade. O texto, que para Lutero passa a ser um espaço de manifestação do sagrado, é o meio, o profano onde o divino se manifesta e revela sua mensagem. A fundação de uma nova realidade fica evidenciada no novo entendimento de uma passagem bíblica reinterpretada sob nova ótica e que leva Lutero a ver toda a escritura em uma nova face; "Assim como antes eu havia odiado violentamente a frase 'justiça de Deus', com igual intensidade de amor eu agora a estimava como a mais querida" 30 .

Apesar de tratar-se de uma experiência com alguma dose de intelectualidade, o próprio Lutero revela o quanto a experiência místico-existencial está imbricada nesse acontecimento. Primeiro ele confessa que não amava o Deus justo, que pune os pecadores, mas o odiava e ele se sentia pecador. Depois do acontecimento, ele se sentia renascido, ou seja, sua existência íntima e pessoal foi modificada. Trata-se de uma hieropatia, ou seja, um sentimento ou correspondência do indivíduo envolvido na hierofania e que 'experimenta o divivo e é por ele transformado. Lutero se sente envolvido em um nível absolutamente religioso já na hierofania do raio, mas especialmente no contato direto com o texto sagrado de tal forma que, mais tarde, ao escrever a respeito da expressão contida no credo apostólico 'Creio na remissão dos pecados' ele afirma: “Não é suficiente crer, de um modo geral, que Deus perdoa os pecados, pois nisso os demônios também creem, mas é preciso crer que eles são perdoados para você, sim, para você pessoalmente" 31 .

\section{Considerações Finais}

Em todos os relatos supracitados em que se descreve a 'gênese' daquilo que é considerado como ponto de partida e centro da teologia de Lutero evidencia-se dois aspectos fundamentais. O primeiro deles é a presença de uma experiência numinosa em que se evidencia a experiência místico-existencial, o sentimento de impotência ante a divindade e a beatitude da graça e fé. O segundo é a (re)descoberta intelectual ligada, tanto no relato do próprio Lutero como nos relatos de historiadores, a uma hierofania em que o Deus se revela, se manifesta, no, e por meio do texto sagrado instaurando, assim, uma nova realidade; “Então me senti como renascido, e entrei pelos portões do próprio paraíso" 32.

\footnotetext{
LUTERO, 1984, p. 30.

LUTERO, 1984, p. 30.

LUTERO apud JUST, 2003, p. 52.

32 LUTERO, 1984, p. 30.
} 
Esses dois aspectos, entretanto, estão profundamente imbricados chegando, até mesmo, a ser arrolados numa mesma e única experiência. É notório, entretanto, que a descoberta intelectual que proporciona o sentimento descrito por Lutero marca, na realidade, o clímax de uma longa busca pessoal, íntima e subjetiva do ser - a pessoa de Lutero - por um relacionamento pessoal pleno com a divindade. Como Paulo no caminho de Damasco ${ }^{33}$, ou como aqueles discípulos a caminho de Emaús ${ }^{34}$, Lutero sentiu o coração 'se aquecer' ao sentir uma íntima ligação entre a mensagem do evangelho e sua existência - vida pessoal. Não foi simplesmente a crença ou a descoberta de um dogma, mas uma transformação, um sentimento íntimo e apaixonado que se agarra à divindade num ato de absoluta confiança e fé.

Fica evidenciado nas diversas narrativas citadas que as experiências pessoais e íntimas do reformador tiveram, de fato, consideráveis influências para o desencadeamento de todo processo reformatório que deu origem ao protestantismo. Lutero tratou de desencadear uma reforma na maneira como o ser humano se relaciona com o sagrado e no modo como este interpreta as irrupções desse sagrado no mundo profano. Para ele, mesmo a palavra falada na escritura sagrada cristã, no sermão e no sacramento, é "uma Palavra que 'retumba descendo do alto' [...]"35 que, não obstante, transforma o íntimo do ser.

\section{Referências}

BÍBLIA. Português. Bíblia sagrada. Tradução de João Ferreira de Almeida. São Paulo: Sociedade Bíblica do Brasil, 2012. Edição Revista e Atualizada.

DREHER, Martin N. História do povo de Jesus. São Leopoldo: Sinodal, 3013.

ELIADE, Mircea. O sagrado e o profano. Trad. Rogério Fernandes. São Paulo: Martins Fontes, 1992.

FEBVRE, Lucien. Martinho Lutero, um destino. São Paulo: Três Estrelas, 2012.

JUST, Gustav. Deus despertou Lutero. Porto Alegre: Concórdia, 2003.

LAWSON, Steven J. A Heroica Ousadia de Martinho Lutero. São José dos Campos: Fiel, 2013.

LUTERO, Martinho. Pelo Evangelho de Cristo: Obras Selecionadas de momentos decisivos da Reforma. Porto Alegre: Concórdia; São Leopoldo: Sinodal, 1984.

São Leopoldo: Sinodal, 1992.

Martinho Lutero: Obras Selecionadas. Vol. 01. Porto Alegre: Concórdia;

33 BÍBLIA. Português. Bíblia sagrada. Tradução de João Ferreira de Almeida. São Paulo: Sociedade Bíblica do Brasil, 2012. Edição Revista e Atualizada, Atos 9.

34 BÍBLIA, 2012, Lucas 24.32.

35 WATSON, Philip, S. Deixa Deus ser Deus. Trad. Paulo F. Flor, Canoas: Ed. ULBRA, 2005. p. 248. 
. Martinho Lutero: Obras Selecionadas. Vol. 07. Porto Alegre: Concórdia;

São Leopoldo: Sinodal, 2000.

OTTO, Rudolf. O Sagrado. São Leopoldo: Sinodal; Petrópolis: Vozes, 2007.

WATSON, Philip, S. Deixa Deus ser Deus. Trad. Paulo F. Flor, Canoas: Ed. ULBRA, 2005. 